This is a self-archived version of an original article. This version may differ from the original in pagination and typographic details.

Author(s): Mathies, Charles; Ferland, Chris

Title: Innovative Strategic Planning for the Institution

Year: 2017

Version: Accepted version (Final draft)

Copyright: (c) 2017 Taylor \& Francis

Rights: In Copyright

Rights url: http://rightsstatements.org/page/lnC/1.0/?language=en

Please cite the original version:

Mathies, C., \& Ferland, C. (2017). Innovative Strategic Planning for the Institution. In K. Powers, \& P. J. Scholss (Eds.), Organization and Administration in Higher Education (2nd ed., pp. 105-

122). Routledge, Taylor \& Francis Group. https://doi.org/10.4324/9781315630656-6 


\title{
Innovative Strategic Planning for the Institution
}

\author{
Charles Mathies and Christopher Ferland
}

When Hurricane Katrina hit New Orleans in late August of 2005, it wrought destruction on a scale unseen before or since in the United States. More than 1,800 people lost their lives, and damages totaled over $\$ 108$ billion (Knabb et al., 2011). In the immediate aftermath of the storm, medical workers and local hospitals were overwhelmed with patients and struggled to provide care (Fink, 2009). One of the more publicized situations occurred at Memorial Medical Center. With the hospital's power supply fading, doctors had to make life and death decisions while treating many ill and injured patients without evacuation assistance (Fink, 2009). The story of Memorial Medical Center brought to light questions about who gets care in a crisis, when they receive it, and how this is decided.

Memorial Medical Center had developed triage protocols as part of its strategic planning for disaster preparedness. However, the protocols provided little guidance during this crisis, as most of the staff were not adequately familiar with them and a number of situations transpired that the protocols did not even address (Fink, 2009; Sweeney, 2014). Ultimately, decisions were made under the guise of doing "the most good with the limited pool of resources" (Fink, 2009). Put another way, attending doctors' professional opinions determined who got treatment at the expense of another. Some doctors based their decisions on the number of lives that could be saved, while others used the number of years of life that could be saved, thus focusing on the healthiest and youngest patients. Analyses of the decisions made at Memorial Medical Center in the aftermath of Katrina, including the euthanizing of some patients (Fink, 2009; Sweeney, 2014), makes it clear that better planning, training, and communication could have enhanced staff's management of triage and, in turn, possibly saved more lives (Sweeney, 2014).

Higher education institutions rarely face life or death situations, but the story above highlights the importance of strategic planning and its execution: a strategic plan is of little use without a means of implementation. However, while implementation is one of the more difficult aspects of strategic planning, it is certainly not the only challenge. The literature on strategic planning has been primarily grounded within the disciplines of business and economics. Some of the classic publications include Alfred Chandler's Strategy and Structure (1962), H. Igor Ansoff's Corporate Strategy (1965) and Strategic Management (1979), and Michael Porter's Competitive Strategy (1980). The classic business components of strategic planning include the formation of a plan, consideration of various viewpoints and constraints both inside and outside of the organization, and integration of the plan and its principles into all functional areas of the organization (Freeman, 2010).

Modern business literature expands the classic definition of strategic planning to include its dynamic nature. Strategic planning is now seen as a process that details how an organization will execute a deliberate strategy; i.e., where an organization intends to position itself in the future and how it will get there (Macintosh \& Maclean, 2015; McClean, 2015). Strategic 
planning is still seen as a fundamentally cyclical process, but one where the cycles, or phases, are shorter due to an environmental context of globalization and instant communication. The literature often makes a distinction between strategic planning and strategic management. Strategic management encompasses more than just planning because it links strategy formulation and implementation with evaluation, adoption, and achievement (Dooris \& Rackoff, 2012). The key concept is that intentionality lies at the heart of both strategic planning and its management (Dooris \& Rackoff, 2012).

Within higher education, strategic planning has been conceived and defined in similar ways as in the business literature. However, if one can generalize, more attention is paid to external stakeholders (government and accountability measures) and environmental influences (diminishing availability of resources and increasing competition) (see Chaffee, 1984; Dooris et al., 2004; Dooris \& Rackoff, 2012; Hinton, 2012; Keller, 1983; Servier, 2000; Schram, 2014; Tolime, 2005; Welsh et al., 2006; and Yeager et al., 2013). George Keller's (1983) Academic strategy: The management revolution in American higher education is recognized as perhaps the first book on strategic planning in higher education, and has been highly influential (Dooris et al., 2004; Dooris \& Rackoff, 2012; Hinton, 2012). Keller (1983) wrote that while strategic planning requires buy-in from all areas of the institutional community, there is no secret formula that can be applied to every institution and every situation. What works at one college or university will not necessarily work at another, as the history, available resources, leadership, and, perhaps most importantly, culture varies from institution to institution.

Peter Drucker, one of the most famous thinkers on organizational management, is famously attributed to the quote, "culture eats strategy for breakfast" (McGregor, 2015). If organizational strategy is breakfast, then its structure is often lunch since institutions typically link their structure to their strategy. No matter how well conceived a strategy may be it will never come to fruition if it doesn't recognize the prevailing institutional culture. A strategy that ignores institutional culture may not attract the attention and buy-in of those intended to implement it (Hinton, 2012). There is often a tension between an institution's strategy and its culture; a new organizational structure or strategy will not necessarily create a new culture. Institutional culture is a messy blend of attitudes, beliefs, and norms, while organizational structure and strategies are more clearly defined. Culture is the environment in which an institutional strategy either thrives or dies. Successful administrators improve their units by addressing the shortcomings within the existing institutional culture.

In practical terms, strategic planning should be more concerned with "doing the right things" than with "doing things right" (McClean, 2015). "Doing things right" occurs at the operational and tactical planning level. Put another way, strategic planning focuses on "what we do"; operational and tactical planning focuses on "how we do it" (Hinton, 2012, McClean, 2015). In higher education, operational planning often takes place within departments or colleges, while tactical planning involves institution-wide policies and procedures necessary for budgeting, assessment, and overall institutional management (Hinton, 2012). 
At its best, strategic planning is visionary and proactive, as organizations should anticipate change rather than adapt after the fact (McClean, 2015). This chapter, while covering the purpose and components of strategic planning in higher education, focuses on the application of the strategic plan. However, a strategic plan cannot be successfully implemented without acknowledging, understanding, and working with the dominant institutional culture.

\section{Purpose of Strategic Planning}

Strategic planning is a set of concepts, procedures, methodologies, tools, techniques, and actions that can help organizations become more successful in defining and achieving their mission, vision, and guiding principles (McClean, 2015). In the last few decades, higher education has faced many changes, such as reduced public funding, evolving student demographics, credential inflation, and new instructional delivery methods (massive open online courses, or MOOCs, for example). It is argued that the best way to manage these changes is through a formalized strategic plan (Swenk, 1999).

Some scholars (Alexander, 2000; Keller, 1993; Shirley, 1988) frame the importance of strategic planning as a compass for navigating continuously changing economic and political conditions. Additionally, there are those who feel that higher education is inefficient and thus requires a formal strategic planning process to assist in maintaining the public's trust. In some states, governing bodies require a strategic planning process in an attempt to please legislative authorities (Watson, 1995). Welsh, Nunez, and Petrosko (2006) stress that strategic planning in higher education has intensified over time due to the changing economic and political conditions and the increased accountability imposed by external agencies from both the state and federal (IPEDS) government and invested $3^{\text {rd }}$-parties (ex: Lumina, Gates, Complete College America).

Chaffee (1984) argues that there are two models of strategic planning in higher education: adaptive and interpretive. The adaptive model treats the institution as an individual entity with its own direction and goals, while the interpretive model acts as a network of participants pursuing similar goals. Institutions using the adaptive approach follow market trends and will often change academic programs in response to supply and demand in the environment. Examples include the current moves toward more health professional programs and online graduate programs. Institutions applying the interpretive model rely on symbolic interactionism, collective realities, and a sense of being. This model often involves selling the institutional story, e.g., Georgia College is the state of Georgia's designated public liberal arts university. The administrators and faculty all believe this story but act in self-interest to pursue their own goals. Chaffee (1984) showed that the adaptive approach alone is less effective than a combined or interpretive approach.

Others approach strategic planning differently, believing that an institution can never accurately predict the future. From that perspective, the primary purpose of strategic planning is to cope with and manage change (Baker \& Martin, 1994). The planning process involves periodic evaluations of the college or university's missions, programs, and goals set against changing internal and external environments in an effort to improve institutional 
effectiveness (Baker \& Martin, 1994; Schmidtelin \& Milton, 1990; Swenk, 1999). Many accreditation agencies include strategic planning in their recommendations and reviews for affirmation and reaffirmation. Reviewing goals annually ensures that institutions will deliver quality education and services enabling them to be more fluid in their planning and adjust quickly to changes in the environment. Additionally, these reviews allow for accomplished goals or new priorities to be dropped, modified, or added into the strategic plan. However, annual reviews are often reactionary and not strategic in nature. The future rarely looks just like the past. If it did then reviews and straight-line projections from the past would work perfectly for future planning (McClean, 2015). Therefore, strategic planning needs to be more than annual reviews and for making minor adjustments to the institution's operations.

Colleges and universities should avoid narrowly focusing on measuring efficiency when the real emphasis should be on measuring effectiveness (Swenk, 1999). Institutions face scrutiny for everything from student achievement and student learning outcomes to financial efficiency. To meet the needs of statutory, constitutional, and legislative reporting, they increasingly rely on institutional data and analysis (Clagett, 2004). These external reporting requests correlate with what administrators usually wish to improve: retention and graduation rates, alumni giving, space utilization, low-producing programs (credits and degrees), and faculty tenure and promotion information (scholarship, teaching, and public service). However, the financial environment and reduction in spending on higher education in many states has caused many administrators to focus only on efficiency. A well-structured strategic plan though makes it possible to track and measure quality, improving overall institutional effectiveness.

\section{$\underline{\text { Key Stakeholders }}$}

The strategic planning process requires commitment and participation from the entire institutional community. Welsh, Nunez, and Petrosko (2006) argue that for a strategic plan to be successful, campus-wide buy-in from administration, faculty, staff, and students is essential. In particular, faculty require transparency, communication, and planning activities with senior administrators; without faculty support, senior administrators find that most of their strategic plans never reach the sought level of success (Garmon, 1984; Rhoades, 2000; Welsh et al., 2006). When contemplating a strategic plan, administrators should invite all community members (faculty, staff, and students) to participate in every step of the process through open dialogue and written documentation. While it would be naive to believe that all participants will agree on how to proceed (Delprino, 2013), a transparent means of gathering input from the campus community creates a sense of openness and shows that administrators are listening to concerns even when it is not possible to incorporate all ideas into the plan.

It is important to establish a relatively small steering committee to oversee the development and assessment of the plan. In most institutions, the faculty and/or staff senate should be involved in selecting individuals to serve on the various planning committees. Without the participation of members of these two key groups, the strategic plan will have limited success. Administrators provide a comprehensive view of the institution that faculty and staff do not possess because of their specific departmental or program responsibilities (Delprino, 
2013). This said, administrators should not lead the planning process but rather help manage it from a distance while a selected faculty member has direct charge (Delprino, 2013). This style often creates buy-in from faculty, thus enhancing the chances of a successful implementation.

When evaluating people to serve on the steering committee, it is necessary to consider a variety of stakeholders, all of whom are important to the institution in some fashion. These stakeholders may include student representatives, alumni, development officers, finance personnel, facilities staff, student affairs professionals, institutional research staff, faculty, and administrators. Depending on its governance structure, an institution may wish to invite representatives from unions, governing boards, and even accreditation bodies (Delprino, 2013). Inclusion of student representatives means balancing their expectations with those of the administrators, faculty, and staff. Students deserve the ability to provide input and share in the process, though they shouldn't be allowed to bog down the conversation with an undue focus on common student complaints (valid or not) such as dining service quality, parking, course availability, and increased costs.

Finding the right size of the steering committee requires a delicate balance. A group that is too large can be unruly, yet a group that is too small can be deemed controversial and handpicked. Many authors feel that a committee of 15 to 20 people works well, with each member sitting on a subcommittee in their area. One frequent concern is individual agendas and priorities. Awareness that committee members are pushing an agenda requires an astute chair or co-chairs. If an agenda is identified, it should be addressed with sensitivity keeping the strategic process flowing. Examples of such agendas include reducing the teaching workload, asking for more tenure-track versus limited-term adjunct lines, and seeking increased compensation for service work. Finally, the steering committee should remain intact for the duration of the strategic planning process.

Clagett (2004) contends that decision support units such as institutional research and institutional assessment (or effectiveness) offices can contribute to strategic planning in a variety of ways. There are many institutions where institutional research and institutional assessment offices operate under the same umbrella. The professionals in these areas have ready access to institutional data and skills to provide useable information. Clagett (2004) uses enrollment forecasting, trend analysis, and institutional assessments as examples of this. If such individuals are not formally a part of the strategic planning committee, they should be in constant contact with the committee and serve in a support function.

\section{Developing, Implementing, and Managing the Strategic Plan}

The literature on strategic planning both in business (see Freeman, 2010; Macintosh \& Maclean, 2015; McClean, 2015 as examples) and in higher education (see Dooris \& Rackoff, 2012; Hinton, 2012; Welsh et al., 2006; and Yeager et al., 2013 as examples) describes a range of phases or stages. For some authors, strategic planning has as few as two stages; others have detailed five, six, or more. In our view, there are three distinct phases of strategic planning in higher education: development, implementation, and management. While each 
phase is unique, they are all interconnected and build on one another. If there is a failure in one, then the entire process is likely to fail, as all three phases are essential (and need to be completed) for strategic planning to be successful.

During the first phase, strategic plan development, three main questions must be answered:

1. What is our current state?

2. Where do we (as an institution) want to be?

3. How do we get there?

These three questions are "strategic" in nature and focus on "doing the right things" as opposed to "doing things right" (McClean, 2015). "Doing things right" is a more appropriate focus in the operational or tactical stages of planning, as these address what the institution "does" (Hinton, 2012). These questions are the foundation from which everything in the strategic planning process should derive.

As indicated by the first question, strategic planning begins with examining where the institution is at currently. An in-depth analysis needs to occur to determine the present status of all aspects of the institution, from facilities, faculty and staff, and finance to undergraduate and graduate curriculum, admissions, and student affairs. The list of areas included in the analysis will differ by institution, but a holistic review must take place so the plan is not limited to just one area, which in most institutions tends to be academic affairs.

Additionally, the mission statement, values (or principles), and vision must be thoroughly reviewed, as these items inform the development of the plan (Hinton, 2012). The mission statement indicates the purposes and operation of the institution. Over time, mission statements have become shorter and more direct (Hinton, 2012). Hinton (2012) claims that comprehensive mission statements create limitations in planning due to their breadth, complexity, mission creep, and focus on institutional culture. We argue that a concise statement that targets specific areas or goals in one page or less works well when planning. A good value statement relays the culture and beliefs of the institution to the reader, while the vision statement outlines where the strategic plan should take the institution. The planning process begins upon reviewing, reframing, and gaining consensus on these items across all stakeholders.

The next step is to understand where institutional leadership wants to go in the future. The senior administrators and/or board typically provide targets for the next five to ten years. These ideas will usually be very specific, requiring the steering committee to broaden them with underlying objectives. It should be noted that chasing rankings is an inappropriate approach. The rankings themselves are often problematic, and pursuing them can have negative impacts (see Hazelkorn, 2015a, and 2015b for details).

Once an institution has determined its present state and desired future, it must plan how to reach its goals. This may be the most time-intensive part of developing the strategic plan. Multiple approaches exist, with some institutions forming steering subcommittees to address specific topics, such as student success. In other cases, the work may be performed by the 
whole steering committee, operating with transparency through open forums or drafts placed on a website. Either approach works, but the key is to create a map detailing how to achieve the larger goals through smaller objectives. For example, an institution wishing to increase retention and graduation rates by ten percentage points may attempt to achieve this goal through such varied means such as enhanced advising strategies, earlier identification of D/F/W grades, increased faculty mentoring, expansion of undergraduate research, and modified residential living requirements.

While the higher education literature presents many examples and concepts from which institutions can draw, (see Cowburn, 2005; Dooris \& Rackoff, 2012; Hinton, 2012; Keller ,1983; Yeager, J. et al., 2013), we argue that there are three tangible elements or "tasks" in this phase. First, a strategic planning document needs to be produced. This document should be visionary and comprehensive, yet simple and easily understood. In particular, the terminology and word choices need to be clear and be aligned with the institution's culture and context. Successful strategic planning documents typically contain four to six goals with approximately a dozen initiatives (Hanover Research, 2013). Goals can address themes common among the constituents and are often suggested by the steering committee.

It is important for the strategic planning document maintain a mission focus, rather than a flexible plan, for consistent improvement over time (Aloi, 2005). A successful process of constant improvement stems from sound, measurable goals and objectives aligned with a periodic assessment plan (Aloi, 2005). When drafting the plan, the steering committee should ensure that the periodic assessments will make it possible to determine whether a particular goal was met (Hanover Research, 2013). The flexibility provided by periodic assessment offers greater utility to the institution than long-term plans measured only at five or ten years. This is especially true in today's quickly changing policy and social media world, where information moves so much more quickly than in the 1970s and 1980s.

The second task is to clearly communicate the strategic vision to the entire institutional community. For a strategic plan to be successful, everyone at every level must understand the strategic vision and the disconnect in communication among organizational levels is the number one reason why strategic plans fail (McClean, 2015). Within higher education, this includes senior institutional leadership, trustees, faculty, staff, and students. As shown in the Memorial Medical Center example, neglecting to communicate the strategic vision and goals throughout the organization dooms a plan for failure. In contrast, a good strategic plan is a "living document" and becomes ingrained in the institutional culture (McClean, 2015).

The third and final task is to create an implementation plan that includes actionable tasks, measurements, and objectives complete with target dates for implementation and milestone checkpoints (McClean, 2015). Above all else, the implementation plan needs to be directive, clear, and comprehensive (Hinton, 2012).

During the second phase, implementation, four core questions must be answered:

1. How much will it cost? 
2. What is our institutional mission and culture, and how does our planning connect to them and to the needs of the state and our stakeholders?

3. What are our target dates for measurements and completion?

4. Who is responsible for getting us there?

These four questions are excellent guides for institutions as they implement their strategic plan (Hinton, 2012; McClean, 2015; and Wells 2015). These questions are more operational and tactical than strategic, as they look to "do things right" rather than "doing the right things" (Hinton, 2012; McClean, 2015). While there are distinct differences between operational and tactical planning, both are outcome focused and are needed to achieve an institution's goals and vision (Hinton, 2012; McClean, 2015). These questions are often embedded in the implementation plan, and the answers to them will evolve over time as people change positions, new information becomes available, or new policies are enacted by the state or institution.

The financial costs of executing a strategic plan and achieving its goals require that the plan be directly linked to the budgetary process (Hinton, 2012). Starting new or altering current programs to meet strategic objectives takes financial resources and often involves multiyear commitments. Sufficient dedicated financial resources are thus required to effectively meet institutional strategic objectives (Hanover Research, 2013). Including projected costs in the strategic plan is a simple and clear way to help ensure that strategic goals become a reality.

The impact of the institution's mission, history, and culture on strategic planning cannot be overestimated (Hinton, 2012). As few colleges and universities have similar missions and histories, each exhibits its own unique culture (environment and context). When institutions respond to external forces, it is referred to in the literature as an adaptation; when they implement a new program or practice it is called innovation; when they mimic or "borrow" from others, it is called isomorphism (Kezar, 2013). Institutions often "borrow" ideas and practices from other institutions and try to incorporate these into their strategies and policies. Implementing a strategic plan and measuring progress towards its goals requires an understanding of the institutional culture (James 2012; Mathies 2015). Challenging and changing institutional culture is a difficult and complex process; it takes time, evaluation of available options, and planning (Farkas, 2013; Hinton, 2012; Kezar, 2013; Kezar \& Eckel, 2002). Consequently, what works for one institution to meet strategic objectives will not necessarily work for another. An institution's strategic initiatives need to be linked to its unique mission and structures and fit within its culture and norms.

Target dates in the implementation plan serve as checkpoints and provide a specific timetable for the completion of various actions, such as the development of programs or policies. The measures or data that will be used to assess the implementation of the strategic plan should be specified. Many institutions use planning calendars or clocks as a visual tool to keep reminded of key target dates (particularly for reoccurring events or milestones).

While developing, implementing, and managing the strategic planning process involves many people across the institution, usually an individual or small group becomes the "face" of 
planning as it is beneficial to have a "face" or a "home" to steward the planning process (Hinton, 2012). At the institutional level, it is often the responsibility of an official committee to monitor, recommend changes to, and generally manage the strategic plan (Yeager et al., 2013); however, a small group or an individual performs the bulk of the work (Hinton, 2012). Adding strategic planning tasks ad hoc to someone's duties or addressing the tasks intermittently is never successful in the long term. The synergy created when an individual or a small group is able to provide context and linkages across divisional and departmental silos is invaluable in implementing and managing the strategic plan (Hinton, 2012).

In this third phase, managing the strategic plan, four key questions need to be answered:

1. Are goals being achieved or not?

2. Are the goals and objective still realistic?

3. Are target dates being met? If not, why and is there a need to readjust the targets?

4. Are there adequate resources available to meet the goals?

These four questions are extremely useful guides for institutions measuring their progress towards meeting strategic objectives (McNamara, 2007; Yeager et al., 2013). Sometimes referred to as the monitoring phase, the managing phase is often the longest in duration and can last months and even years. One common development in this phase is the "adaptation to" the current assessment cycle and culture at an institution. An assessment cycle is a regular schedule of assessments and modifications to university initiatives and programs (Hinton, 2012); examples include program review and financial/budget requests and evaluations.

Part of managing the strategic plan is making sure an assessment cycle is functioning, complete with a feedback loop. This is done by reviewing evaluation results and adjusting the strategic plan accordingly. A feedback loop informs institutions how effectively their plans are fulfilling their institutional mission and planning goals (Middaugh, 2009). The feedback loop is "missed" or is "incomplete" when assessments and evaluations are not integrated back into the institution's system of self-regulation and improvement (McClean, 2015; Middaugh, 2009). The success of a strategic planning process requires continual progress monitoring and integration of the results of evaluations back into the plan.

If resources, both financial and human, are being dedicated to fulfill the strategic initiatives, it is important to measure the initiatives' success via data, metrics, and analytics (McClean, 2015). The generation, collection, and use of data, metrics, and analytics should tie directly into the strategic plan. Intentionality and relevance of what is collected and used is key; including peripheral data only adds to the clutter and creates confusion as to the primary goals and purpose of the institution and its strategy (Calderon, 2015a). Decision support units such as the information technology (IT), institutional research, institutional effectiveness, and assessment are common sources of data, metrics, analytics, and their analysis. These units form the starting point, as they are often the official sources and keepers of an institution's performance analytics (Calderon, 2015a).

While the contents of the strategic plan vary by institution, there are common themes that stretch throughout higher education. Four areas commonly monitored in strategic planning 
processes are budget (financial resources), human resources, students, and facilities. Budgets at all levels (university, college, and department) can be used as a basis for monitoring how well the plan is being integrated, as they should reflect the strategic goals and priorities of the institution (Hinton, 2012). Sequencing and aligning strategic priorities within the budgetary process allows institutions to check progress towards strategic goals as well as move into a proactive role by anticipating future financial needs and commitments (Breslawski, 2013; Hinton, 2012). The key is the ability to promote budget alignment with strategic goals where appropriate. Showing faculty and staff the importance of prioritizing strategic goals through the funding of academic or non-academic pursuits assists in achieving a campus culture that supports the plan.

The annual personnel review processes should also be linked to the institution's strategic plan. If any part of the plan and its application affects personnel (job security, status, tasks, etc.), the institution and its leaders should pay close attention to their reactions and be prepared to address any issues directly and swiftly (Choban et al., 2008). Once someone, regardless of position, interprets the strategic plan as a threat to their well-being, the entire plan can be jeopardized (Rowley et al., 1997). Personnel reviews can ensure that the institution has enough suitable faculty, support staff, and other employees to meet its shortterm and strategic goals. However, managing personnel of a department, let alone an entire institution is usually more complicated in higher education than in the corporate world (Hinton, 2012) due in large part to the uniqueness of faculty positions (tenure, skill requirements, etc.), the culture of academia and, in the case of public institutions, workplace regulations governing public employees.

The most common ways institutions use student data to monitor their progress towards strategic goals is through examining enrollment goals and trends, the impact of new academic initiatives or programs (typically on academic performance and enrollments), and use of services (support, facilities, activities, etc.). The purpose of higher education, while hotly debated over the years, has students at its core (Altbach, Reisberg, Rumbly, 2009). Whether the goal is to prepare individuals for the labor market, provide a means for personal development, promote an educated citizenry, or produce new research, students are almost always directly impacted.

Facilities are often not fully integrated into the strategic planning process. Faculty members, in particular, are tempted to stop participating in the process as many have little or no interest in planning activities not focused on academics (Hinton, 2012). But their input is important as there is a strong need for facilities that are functional while supportive of the institution's academic initiatives (Hinton, 2012). Incorporation of a facilities master plan into the strategic plan aligns the academic plan with the physical space requirements. This provides a blueprint for the long-range allocation of resources and phasing initiatives so they can be realistically support the current and anticipated needs of students, staff, and faculty (Hinton, 2012).

The frequency of progress monitoring of various aspects of the strategic plan is highly dependent on the institution's culture and available resources. Colleges and universities use scorecards and dashboards to provide "high-level" monitoring of key indicators for each area 
(Hanover Research, 2013). The method and frequency of progress measurement should be detailed within the implementation plan to make clear to the entire institutional community when and how the strategic plan will be monitored. In summary, all four of these areas (budget, personnel, students, and facilities) have a direct bearing on the coordination and use of resources and should thus be measured and monitored (Hinton, 2012). In other words, these four areas are the centerpiece of an institution's operations.

\section{Applying the Strategic Plan: Innovative Considerations}

Colleges and universities have typically been very good at developing strategic plans. There are numerous articles and, books, and other materials that they can use as resources (see Dooris et al., 2004; Dooris \& Rackoff, 2012; Hanover Research, 2013; Hinton, 2012; Keller ,1983; Noel-Levitz, 2009; Servier, 2000; Schram, 2014; Tolime, 2005; Welsh et al., 2006; and Yeager et al., 2013 as examples). The real challenge is to actually apply the plan and put it into action; particularly in ways that are original and address current as well as future issues. While previous sections focused on what goes into strategic planning and who's involved, we now explore three specific areas where an institution can be innovative in applying its strategic plan.

\section{Digital Strategy}

A digital strategy does not have to do with hardware or software; it is a strategy for servicing the "digital consumers" on campuses (Boag, 2014b). Digital consumers are not just students, most of whom are digital natives, but also faculty, staff, senior leadership, and external stakeholders. Digital consumers see and interact differently with the world as they view the virtual and physical as having equal relevance (Boag, 2014b). A key point is that "digital" is more than just the Internet; it is a convergence of the Web, social media, mobile technology, cloud computing, IT security, and information (Boag, 2014a, 2014b; Selingo, 2015). Digital consumers carry their friends and family everywhere they go via apps and mobile phones and have expectations for on-demand service, data, and information (Boag, 2014b).

Most colleges and universities have approached digital strategies by looking inwards, focusing on what they want to say (Boag, 2014a). The result has been a proliferation of content on institutional webpages, much of which is seldom visited. Instead, institutions need to think of their digital strategy with their users' needs in mind. While some argue that colleges and universities already have a good idea of how their community is using and engaging with technology, technology's constant change leaves many institutions playing catch-up (Boag, 2014a). A digital strategy needs to consist of clear and practical ways of addressing the problems and interests faced by digital consumers (Boag, 2014b). Examples of problems include connectivity and band-with issues on campus to not being able to pay for goods and services electronically. Examples of interests include the breath of the library's electronic collections and admissions' informational videos to interacting with fellow students, staff, and their faculty through electronic communications and social media platforms. Institutions need to take a step back, investigate, and try to understand how exactly 
their users expect to engage digitally with the institution and while on the campus (Boag, 2014a).

Mapping the digital user's conception of "campus" is one of the most effective ways to gather information about various touch (interaction) points and user goals (Boag, 2014a). This mapping includes documenting both where and how digital users access the institution's network, including the software or apps used, as well as the integration plans of digital technologies into classrooms and student learning support. Digital strategies should not come from data managers, the IT team, or even decision support units like the institutional research or assessment office. It is the senior leadership's responsibility to develop and integrate a digital strategy guided by the institution's strategic vision. The digital strategy ultimately needs to be more than a set of vague goals about meeting users' technology needs; it should be a detailed plan to integrate the concept of "how technology is used" within an institution's strategic planning, culture, and organizational structures (Boag, 2014b).

When applying strategic planning to institutions with limited physical campuses (i.e. online) one needs to be considerate of student access, convenience, instructional delivery methods, and program development (Xu and Jaggars, 2011). These institutions need long-term strategies to manage the growth of online courses in order to establish quality programs while ensuring student success. Student support services, such as financial aid, registrar services and library, need to exist for full or partially online programs with an emphasis on convenience and engagement. A reduction in either of these services hiders the overall effectiveness and value of the program.

Distance learning may seem relatively simple to implement, however reality is to be successful an interdisciplinary approach across the campus and IT needs to occur. This is true for online only as well as multi-campus and "traditional" institutions with an online presence. The relationships between IT, faculty, and student services need to be open and inclusive. Distance learning requires professional development in terms of information technology, instructional delivery, classroom structure, and assessment. Teaching online courses occurs in a fluid environment with continually technological improvements during the term the course is being delivered.

\section{Consideration of Current and Future Student (and Staff) Technology Needs}

There is ample evidence that a number of technological innovations are already "disrupting" many of the traditional ways colleges and universities provide teaching, services, and support, such as library services, to their students, faculty, and staff (Calderon, 2015b; Selingo, 2015). These disruptions have created new modes and types of interactions between institutions and their community members (students, staff, and faculty), altering many longheld norms and conventions (Calderon, 2015b). Today's students represent the first generation to grow up with the Internet and mobile technologies (Prensky, 2001, 2010). As such, current and future students have been called "digital natives" and expect to interact with institutions, both in and out of the classroom, via technology (Autry \& Berge, 2011; Calderon, 2015b; Prensky, 2001, 2010). However, most faculty and staff are "digital 
immigrants," those who, while not born into the digital world, have adopted many aspects of technology into their professional and personal lives (Autry \& Berge, 2011; Prensky, 2001; 2010). An important distinction between the two groups, digital natives and immigrants, is that while some immigrants may adapt to technology better than others, they never attain native fluency and always retain to some degree their "accent" or past way of doing things (Prensky, 2001). An example of this seen in the classroom; immigrants may adopt new technologies into how they teach and interact with their students, but their pedagogical perspective remains rooted in they were trained which was based on traditional lectures and face-to-face interactions (Autry \& Berge, 2011). In short, the differing needs, abilities, and expectations of digital natives and immigrants have created disconnects between what students want and what institutions provide.

The contrasting communication styles of natives and immigrants are a great example of how the disconnect plays out in the classroom. Digital natives prefer to receive information fast, connecting to and engaging with a "network" of others all while multitasking with various social media and academic work (Prensky, 2001, 2010). Conversely, most teachers, who are still predominantly digital immigrants, feel more secure delivering traditional lectures and assigning reading materials straight from textbooks and journals (Prensky, 2001). The literature assessing the positive and negative aspects of the digital native/immigrant divide in higher education (see Bennet et al., 2008; Helsper \& Enyon, 2009; Smith, 2012; Thomas, 2011 as examples) makes clear that teachers, regardless if they are digital immigrants or natives, can "speak the same language" as their students if they continually integrate new technologies into their pedagogical and curriculum planning. Institutions should find ways for their teachers and students to "partner" in the teaching/learning process (Prensky, 2010) while at the same time support and encourage faculty (and staff) development in the use of new educational technologies.

The consideration of future technology needs is similar to and often overlaps the digital strategy. However, they are two distinct and separate matters. Digital strategy focuses on "how" and "where" students and staff are using technology, while the consideration of future technology focuses more on "why" or "for what purpose" they are doing so. Both concepts should be addressed in the strategic planning process. This is becoming more critical as time passes, because the expectations of using technology on campuses are increasing. Digital natives are no longer just students, they are also the newest generation of staff and faculty, and more are coming every year.

\section{Student Learning Outcomes}

Student learning outcomes "are statements of what a learner is expected to know, understand, and/or be able to demonstrate at the end of a period of learning" (Adams, 2008, p.4). They have often been linked to assessments of quality of education and are concerned with outcomes of the educational process (Adams, 2008). At the most basic level, these assessments suggest that success occurs when learning goals are identified and corresponding curriculum is developed and then competently taught (Breslawski, 2013). Two of the most traditional methods to measure quality of education have been student-to-teacher ratios and 
course evaluations (Calderon, 2015a). Despite the fact that both measures are limited and have serious methodological issues (Calderon, 2015a) student learning assessments have increasingly found importance in regional and programmatic accreditations (Breslawski, 2013). In fact, many accreditation agencies now require institutions to measure student learning outcomes as part of the accreditation process. However, some of the newer methods introduced have been large-scale national assessments such as the Collegiate Learning Assessment (CLA) and the National Survey of Student Engagement (NSSE), which have their own methodological issues or limitations (Chen \& Mathies, in press). This has left institutions needing to think more holistically and strategically in their approach to assessing student learning outcomes.

It is also quite common for an institution or system to "borrow" novel ideas or best practices from another in an effort to improve student learning. Adopting an external assessment method or tool requires additional work; the institution must first consider the compatibility of its organizational structure and culture (Chen \& Mathies, in press; Mathies, 2015). As discussed previously in this chapter, organizational culture is perhaps the biggest issue to be addressed in developing a successful strategic plan or adopting a policy or program from another institution or department. A student learning assessment tool that is effective in one setting might be totally inadequate in another (Chen \& Mathies, in press).

This leads us back to the strategic planning process and selecting metrics used to measure student learning. While student learning outcome assessments are not new or innovated per se, what is new though is having a comprehensive approach assessing student learning and its inclusion in the strategic planning process. Many institutions and state systems struggle to implement "good" assessments of student learning and a large variation exists amongst institutions in their standards, practices, and procedures (Chen \& Mathies, in press). It is not uncommon to find student learning outcome assessments piecemealed together over time. This often happens as "new" ideas or assessment goals (a recent example is workforce development) gain in popularity and influence. The result is that institutions need to incorporate into their strategic planning process not only how to assess student learning outcomes (assessment tool/practice) but also why (philosophically) they assess.

Assessment of student learning is difficult, and there is no "one size fits all" approach for colleges and universities or even departments given the significant differences amongst institutions as well as amongst disciplines (Breslawski, 2013). Therefore, multiple methods of assessing student learning should be embedded in regular institutional assessments as well as in the strategic planning process. There are two distinct ways in which assessment can be employed to improve student learning and outcomes (Chen \& Mathies, in press). First, personalized learning assistance should be provided to students through assignment and course feedback (grades, pre/posttest evaluations, etc.), while career centers should offer career and psychological tests to help students identify professional interests and align course and degree choices. Second, organizational change should occur where individual results aggregated from assessment tools such as the CLA and NSSE present an organizational picture that indicates areas for improvement. In summary, student learning assessments must 
be proactive in nature and include multiple measures which are embedded in the various stages of the strategic planning process.

\section{Conclusion}

Strategic planning is a process; not a document (Dooris \& Rackoff, 2012). While documents and metrics are certainly developed and used, these should not be the focus. Instead, attention should be centered on developing a vision or goal-based planning model that can help guide an institution into the future. The strategic planning process, though, is a difficult and timeconsuming endeavor. It also impacts people, and where people are involved, there are politics (Delprino, 2013). On many levels, strategic planning is a political process; within an institution, the effective use of politics can facilitate change and help the campus community adapt to any accompanying uncertainty, thereby minimizing dissonance (Delprino, 2013). A balance must be struck between a commitment to the strategic planning process and the realities of the institution's situations (Delprino, 2013). In our view, the ultimate success of a strategic plan depends on how well it fits within the institutional culture.

Colleges and universities should identify what they are good at and leverage those strengths into new opportunities. When developing a strategic plan, leadership should be careful not to limit the potential of the institution through overregulation, forcing it to operate as it has in the past or in traditional ways. Rather, the strategic planning process is about introducing and managing change. Changes, especially strategic ones, need to be undertaken with careful consideration not only to the institution's strengths, but also to its traditions, character, and culture (Delprino, 2013). The strategic planning process should change an institution for the better, leading its students, staff, and faculty in a clear, desirable, and engaging direction.

\section{Discussion Questions}

1. What are the three key phases of strategic planning? Why are they each important?

2. How are data and its analytics used in strategic planning?

3. Why is understanding the institutional culture important in strategic planning?

4. What are key obstacles in developing a strategic plan?

5. Who are the various stakeholders in strategic planning and how do they fit into the planning process?

6. What is the difference between "strategic" planning and "operational" or "tactical" planning?

7. What is the first step in developing a strategic plan? Why is this important?

8. What should an institution do before implementing an idea or best practice "borrowed" from another institution?

9. How are target dates important and influential in the strategic planning process?

10. How does your institution address (or acknowledge) the three suggested innovative considerations (digital strategy, current and future technology needs, and student learning outcomes) in its strategic planning process? 


\section{References}

Adams, S. (2008). Learning outcomes current development in Europe: Update on the issues and applications of learning outcomes associated with the Bologna Process. In Bologna seminar: Learning outcomes based higher education: The Scottish experience. Retrieved from: http://www.ehea.info/uploads/seminars/edinburgh_feb08_adams.pdf.

Alexander, F. K. (2000). The changing face of accountability: monitoring and assessing institutional performance in higher education. Journal of Higher Education, 71, 411431.

Aloi, S. (2005). Best practices in linking assessment and planning. Assessment update. 17(3) 4-6.

Altbach, P., Reisberg, L., \& Rumbley, L. (2009). Trends in global higher education: Tracking an academic revolution. Report prepared for UNESCO 2009 World Conference on higher education. UNESCO: Paris.

Ansoff, H. I. (1965). Corporate strategy: An analytic approach to business policy for growth and expansion. McGraw-Hill: New York.

Ansoff, H. I. (1979). Strategic management. Wiley: New York.

Autry, A. \& Berge, Z. (2011). Digital natives and digital immigrants: Getting to know each other. Industrial and commercial training. 43(7), 460-468.

Baker, D., \& Martin, R. J. (1994). A framework for strategic planning and change in higher education: The case of a business school. Paper presented at 33rd Annual Forum for Institutional Research, ay 16-19, 1993, at Chicago. (ERIC Document Reproduction Service No. ED 360918)

Bennett, S., Maton, K., \& Kervin, L. (2008). The 'digital natives' debate: A critical review of the evidence. British journal of educational technology. 39(5), 775-786.

Boag, P. (2014a). Higher education \& digital transformation. Blog post. Retrieved from: https://boagworld.com/digital-strategy/the-higher-education-needs-to-face-the-digitalreality/

Boag, P. (2014b). What the heck is 'digital' anyways? Blog post. Retrieved from: https://boagworld.com/digital-strategy/what-the-heck-is-digital-anyway/

Breslawski, S. (2013). Strategic planning when aligning curriculum and resources. In Patrick Schloss \& Kristina Cragg's (Eds.) Organization and administration in higher education. $1^{\text {st }}$ edition. Routledge: New York. 151-176.

Calderon, A. (2015a). In light of globalization, massification, and marketization: Some considerations on the uses of data in higher education. In Karen Webber \& Angel 
Calderon (Eds.) Institutional research and planning in higher education: Global contexts and themes. Routledge: New York. 186-196.

Calderon, A. (2015b). Exploring the future global flows of knowledge and mobility: Implications for international education. In Leasa Weimer's (Ed.) A wealth of nations: 2015 conference conversation starter. EAIE: Amsterdam. 45-52.

Chaffee, E. (1984). Successful strategic management in small private colleges. The journal of higher education. 55(2), 212-241.

Chandler, A. (1962). Strategy and structure: Chapters in history of the industrial enterprise. The M.I.T. Press: Cambridge, Massachusetts.

Chen, P.D. \& Mathies, C. (in press). Assessment, evaluation, and research. In Dennis Roberts and Susan Komives (Eds.) Enhancing student learning and development in crossborder higher education. New Directions for Higher Education. John Wiley \& Sons Inc.: Hoboken, NJ.

Choban, M., Choban, G., Choban D. (2008). Strategic planning and decision making in higher education: What gets attention and what doesn't. Assessment update: Progress, trends, and practices in higher education. 20(2). 1-2, 13-14.

Clagett, C. (2004). Applying ad hoc institutional research findings to college strategic planning. New Directions for institutional research. 123, 33-48.

Cowburn, S. (2005). Strategic planning in higher education: Fact or fiction? Perspectives: Policy and practice in higher education. 9(4), 103-109.

Delprino, R. (2013). The human side of the strategic planning process in higher education. Society for college and university planning: Ann Arbor, Michigan.

Dooris, M., Kelley, J., \& Trainer, J. (2004). Strategic planning in higher education. New directions for institutional research. 123. 5-11.

Dooris M. \& Rackoff, J. (2012). Institutional planning and resource management. In R. Howard, G. McLaughlin, W. Knight (eds.) The handbook of institutional research. Jossey-Bass: San Francisco. 183-202.

Farkas, M. (2013). Building and sustaining a culture of assessment: Best practices for change leadership. Reference services review. 41(1), 13-31.

Fink, S. (2009). The deadly choices at memorial. N.Y. Times. Aug 25. Retrieved Feb 2016 from http://www.nytimes.com/2009/08/30/magazine/30doctors.html.

Freeman, R. E. (2010). Strategic management: A stakeholder approach. Digital printed version. Cambridge university press: Cambridge, U.K.

Hanover Research. (2013). Strategic planning in higher education: Best practices and benchmarking. Author. Retrieved from 
http://www.hanoverresearch.com/media/Strategic-Planning-in-Higher-Education$\%$ E2\%80\%93-Best-Practices-and-Benchmarking.pdf

Hazelkorn, E. (2015a). The obsession with rankings in tertiary education: Implications for public policy. Presentation to the World Bank. Retrieved from https://hepru.files.wordpress.com/2015/01/the-obsession-with-rankings-in-tertiaryeducation_wb_0115.pdf

Hazelkorn, E. (2015b). Rankings and the reshaping of higher education: The battle for world-class excellence. $2^{\text {nd }}$ edition. Palgrave MacMillan: London.

Helsper, E. \& Enyon, R. (2009). Digital natives: Where is the evidence? British educational research journal. 36(3), 503-520.

Hinton, K. (2012). A practical guide to strategic planning in higher education. Society for college and university planning: Ann Arbor, Michigan.

James, G. (2012). Developing institutional comparisons. In R. Howard, G. McLaughlin, W. Knight (eds.), The handbook of institutional research (pp. 644-655). Jossey-Bass: San Francisco.

Keller, G. (1983). Academic strategy: The management revolution in American higher education. Johns Hopkins Press: Baltimore.

Kezar, A. (2013). How colleges change: Understanding, leading and enacting change. Routledge: New York.

Kezar, A. \& Eckel, P. (2002). The effect of institutional culture on change strategies in higher education: Universal principles or culturally responsive concepts? The journal of higher education. 73 (4), 435-460.

Knabb, R., Rhome, J., Brown, D. (2011). Tropical cyclone report: Hurricane Katrina: 23-30 August 2005. National hurricane center.

Macintosh, R. \& Maclean, D. (2015). Strategic management: Strategists at work. Palgrave: London.

Mathies, C. (2015). Transnational IR collaborations. In Karen Webber and Angel Calderon (Eds.) Institutional Research and Planning in Higher Education: Global contexts and themes. New York: Routledge Press. 28-39.

McClean, D. (2015). Strategic planning: As simple as A, B, C. Lulu Publishing Services: Raleigh, North Carolina.

McGregor, C. (2015). The man who invented management. General Counsel. Spring. Retrieved from http://www.legal500.com/assets/pages/gc/spring-2015/the-man-whoinvented-management.html February 2016. 
McNamara, C. (2007). Field guide to non-profit strategic planning and facilitation. Authenticity Consulting Inc.: Minneapolis.

Middaugh, M. (2009). Closing the loop: Linking planning and assessment. Planning for higher education. 37 (3), 5-14.

Noel-Levitz, Inc. (2009). Six essential - and six common mistakes - in cabinet-level strategic enrollment planning. Noel-Levitz executive briefing. Author: Iowa City. Retrieved from:

https://www.noellevitz.com/documents/shared/Papers_and_Research/2009/SixEssenti alsinCabinetLevelSEP0209.pdf

Porter, M. E. (1980). Competitive strategy: Techniques for analyzing industries and competitors. Free Press: New York.

Prensky, M. (2001). Digital natives, digital immigrants. On the horizon. 9(5), 1-6.

Prensky, M. (2010). Teaching digital natives: Partnering for real learning. Corwin: Thousand Oaks, California.

Rhoades, G. (2000). Who's doing it right? Strategic activity in public research universities, The Review of Higher Education, 24(1), 41-66.

Rowley, D. J., Lujan, H.D., \& Dolence, M. G. (2001). Strategic change in college and universities: Planning to survive and prosper. San Francisco: Jossey-Bass.

Schmidtelin, F., \& Milton, T. (Eds.) (1990). Adopting strategic planning to campus realties. New Directions for Institutional Research, no 67. San Francisco: Jossey-Bass.

Selingo, J. (2015). College disrupted: Perspectives on how technology is changing the college education model. The chronicle of higher education: Washington D.C.

Servier, R. (2000). Strategic planning in higher education. CASE: Washington, D.C.

Shirley, R. C. (1988). Strategic planning: an overview, New Directions for Higher Education, 16(4), 5-14.

Smith, E. (2012). The digital native debate in higher education: A comparative analysis of recent literature. Canadian journal of learning and technology. 38(3) 1-18.

Swenk, J. (1999). Planning Failures: Decision Cultural Clashes. The Review of Higher Education 23.1, 1-21.

Sweeney, V. (2014). The story of hurricane Katrina and memorial hospital. Law school student scholarship. Paper 589.

Thomas, M (Ed. 2011). Deconstructing digital natives: Young people, technology, and new literacies. Routledge: New York. 
Tolmie, F. (2005). The HEFCE guide to strategic planning: The need for a new approach. Perspectives: Policy \& practice in higher education. 9(4), 110-114.

Watson, C. (1995). Strategic planning for higher education. Journal of professional issues in engineering education and practice. 121(3) 187-190.

Wells, J. (2015). Planning in a global university: Big challenges and practical responses. In Karen Webber \& Angel Calderon (Eds.) Institutional research and planning in higher education: Global contexts and themes. Routledge: New York. 174-185.

Welsh, J., Nunez, W., \& Petrosko, J. (2006). Assessing and cultivating support for strategic planning: Searching for best practices in a reform environment. Assessment \& evaluation in higher education. 12(3), 693-708.

$\mathrm{Xu}, \mathrm{Di}$, and Shanna S. Jaggars. 2011. "The Effectiveness of Distance Education across Virginia's Community Colleges: Evidence from Introductory College-Level Math and English Courses." Educational Evaluation and Policy Analysis 33 (3): 360-77.

Yeager, J., El-Ghali, H., \& Kumar, S. (2013). A guide to the development of an institutional strategic plan. In Patrick Schloss \& Kristina Cragg's (Eds.) Organization and administration in higher education. $1^{\text {st }}$ edition. Routledge: New York. 127-150. 